\title{
LA FUNCION PUBLICA EN EL PROYECTO DE LEY REGULADORA DE LAS BASES DEL REGIMEN LOCAL (*)
}

$352: 35.08$

por

Raúl Bocanegra Sierra

SUMARIO: I. INTRODUCCION.-II. LOS FUNCIONARIOS LOCALES CON HABILITACION NACIONAL.-III. LA SELECCION, FORMACION Y PROVISION DE PUESTOS DE TRABAJO DE LOS FUNCIONARIOS CON HABILITACION NACIONAL.IV. LOS FUNCIONARIOS PROPIOS DE LAS CORPORACIONES LOCALES.- V. DISPOSICIONES COMUNES A LOS FUNCIONARIOS DE CARRERA.

\section{INTRODUCCION}

El Título VII del Proyecto de Ley Reguladora de las Bases del Régimen local, bajo el rótulo «Personal al servicio de las Entidades locales», extiende su regulación, según señala el artículo 83 del mismo, a los "funcionarios de carrera, contratados en régimen de Derecho laboral, y personal eventual que desempeña puestos de

(*) Texto de la Comunicación presentada por el autor en las Jornadas de Estudio sobre "Organización Territorial del Estado (Administración local)», el día 29 de mayo de 1984, organizadas por la Dirección General de lo Contencioso del Estado, y celebradas en el salón de actos del Banco de España, en Madrid. 
confianza», que son los que, según el mismo precepto, integran «el personal al servicio de las Entidades locales» (1).

Haciendo notar la tendencia a la supresión de la figura de los contratados administrativos (2), y dejando al margen el personal contratado laboral (cuya figura no ofrece mayor complicación que la de la clasificación como tales de los correspondientes puestos de trabajo) (3) y el personal eventual de confianza, vamos a ocuparnos aquí especialmente de los funcionarios al servicio de las Corporaciones locales, examinando algunos de los problemas que en los más diversos terrenos suscita la nueva normativa que incorpora el Proyecto.

La nueva estructura autonómica del Estado, el carácter básico del Proyecto (en el sentido del art. 149, 1, 18, de la Constitución), el principio de autonomía de las Corporaciones locales consagrado en la Constitución, la reforma en marcha del conjunto de la fun-

(1) Esta es una clasificación que altera, en parte, la existente actualmente, no obstante moverse en el marco de la más pura ortodoxia en el mundo de la función pública española. Es en la Ley de Bases 79/1968 donde por primera vez se distingue, en el ámbito local, entre funcionarios de carrera y de empleo, aunque el precepto transcrito del Proyecto retoca la distinción al no aludir a los funcionarios «de empleo» expresamente, sino únicamente a los eventuales.

(2) La disposición transitoria sexta dispone al respecto:

«1. A partir de la fecha de entrada en vigor de la presente Ley no podrán celebrarse por las Administraciones locales contratos de colaboración temporal en régimen de Derecho administrativo, ni renovarse los existentes.

2. En el plazo de seis meses, a partir de la fecha de entrada en vigor de la presente Ley, las Administraciones locales procederán a realizar la clasificación de las funciones desempeñadas hasta ese momento por el personal contratado administrativo.

Esta clasificación determinará los puestos a desempeñar, según los casos, por funcionarios públicos o por personal laboral fijo o temporal.

De la citada clasificación podrán derivarse las modificaciones precisas en la plantilla.

3. El personal que viniera desempeñando con anterioridad al 14 de octubre de 1982 los puestos de trabajo clasificados como permanentes, podrá participar en las pruebas restringidas de acceso que resulten precisas para cubrir las plazas que queden vacantes o sean de nueva creación, que se regirán por lo dispuesto en esta Ley.

4. Mientras existan en vigor contratos administrativos y nombramientos de funcionarios de empleo en cualquier Administración pública, éstos quedarán en suspenso durante el tiempo en que quienes los ocupan desempeñan en la Corporación local un cargo electivo retribuido y de dedicación exclusiva. Durante los treinta días siguientes al cese en estas condiciones, éstos tendrán derecho a reintegrarse en el puesto de trabajo que ocupaban hasta la suspensión, siempre que continuaran dándose las condiciones legales para el establecimiento pleno de las correspondientes relaciones.

Asimismo, conservarán los derechos adquiridos hasta el momento de la suspensión y se les reconocerán, a título personal, los que pudieran haber adquirido durante la misma por aplicación de disposiciones de carácter general».

(3) Es el Pleno de cada Corporación quien, en uso de la autonomía local, aprueba las correspondientes plantillas, que deberán «comprender todos los puestos de trabajo reservados a funcionarios, personal laboral y eventual» (art. 84, 1, del Proyecto). 
ción pública (a través del Proyecto de Ley de Medidas para la Reforma de la Función Pública) o los diversos pronunciamientos del Tribunal Constitucional sobre diferentes extremos de la función pública local, ahora objeto de atención por el Proyecto, son todos ellos argumentos inevitablemente imbricados con la regulación sustantiva del funcionariado local que aquél ofrece y a los que necesariamente habrá que prestar atención, al hilo del examen de las normas que el Proyecto propone, aun tratándose de un análisis provisional (no podría ser de otro modo), como el que aquí se pretende.

\section{LOS FUNCIONARIOS LOCALES CON HABILITACION NACIONAL}

El Proyecto parte de la base de la aceptación de la opción constitucional por el sistema funcionarial para establecer el régimen jurídico básico de los servidores públicos (4), y determina cuáles son las funciones públicas que deben reservarse a los funcionarios

(4) Como tempranamente advirtió T. R. FERNÁNDEz RoDRígUEz: «La organización territorial del Estado y la Administración pública en la nueva Constitución», en Lecturas sobre la Constitución Española, I, UNED, Madrid, 1978, págs. 364 y sigs., aparte de otros trabajos. Claramente en contra de ello, decididamente en favor de la laboralización de la función pública, L. ORTEGA: Los derechos sindicales de los funcionarios públicos, Madrid, 1983, por ejemplo, págs. 43 y sigs. La reciente refundición (y reforma para la local) de la función pública francesa en un solo Estatuto general, llevado a cabo, en sus textos más importantes, por las Leyes de 13 de julio de 1983, sobre derechos y obligaciones de los funcionarios; de 11 de enero de 1984, sobre función pública del Estado, y de 26 de enero de 1984, sobre la función pública territorial (que no han completado, sin embargo, la operación, al constituir solamente los Títulos I, II y III de un completo Estatuto de la función pública), no ha llevado consigo una discusión importante sobre este extremo de la situación legal y reglamentaria de los funcionarios públicos, que ha sido aceptada por las organizaciones sindicales representativas de los funcionarios, abandonando así su tradicional oposición a aceptar la aprobación por Ley de un Estatuto de los funcionarios, lo que ha sido calificado como una de las paradojas puestas de relieve por la aprobación del Estatuto (P. GABORIT: "Droits et obligations du statut général des fonctionnaires de l'Etat et des collectivités locales», $A J D A, 4$ [1984], págs. 180 y sigs., en un número de esa revista dedicado íntegramente a la reforma citada, recogiendo los textos legales y diversos trabajos sobre diferentes extremos de la reforma). Oposición aquella fundada, como señala el autor citado (pág. 180), en la creencia de que tales Estatutos habrían de estar inspirados en una concepción autoritaria de las relaciones entre el Estado y los funcionarios, especialmente por la voluntad de limitar sus libertades a través de la prohibición o la restricción del derecho sindical, del derecho a la huelga o incluso de la libertad de asociación. No parece, sin embargo, que la aprobación de aquel Estatuto, con la anuencia de las organizaciones sindicales de los funcionarios franceses, confirmando su situación legal y reglamentaria, haya confirmado estos temores.

Acerca de las posiciones doctrinales al respecto en Francia y su carácter antiguo, pero marginal, cfr. J. M. AuBY: «L'évolution des sources du droit de la fonction publique», en el mismo número de la Revista antes citada, esp. págs. 246 y 255. 
públicos, entre las que se encuentran las que impliquen ejercicio de autoridad (que son las que incluso aquellos que sostienen la contractualización de la función pública entienden deben, con todo, ser las únicas a desempeñar por funcionarios), aparte de las que característicamente constituyen las propias de los actuales Cuerpos nacionales. La relación de lo que el Proyecto considera funciones públicas es puramente enunciativa, con lo que se abre la posibilidad de dar entrada a las Comunidades Autónomas en la regulación de la materia. El párrafo 2 del artículo 86 señala, en efecto:

«2. Son funciones públicas, cuyo cumplimiento queda reservado exclusivamente a personal sujeto al estatuto funcionarial, las que impliquen ejercicio de autoridad, las de fe pública y asesoramiento legal preceptivo, las de control y fiscalización interna de la gestión económico-financiera y presupuestaria, las de contabilidad, tesorería y recaudación y, en general, aquellas que en desarrollo de la presente Ley se reserven a los funcionarios para la mejor garantía de la objetividad, imparcialidad e independencia en el ejercicio de la funcionn.

Por otro lado, en uso de la amplia libertad de que el legislador estatal dispone para fijar las bases, el Proyecto entiende frente a otras posibles soluciones (no sólo desde la perspectiva de una posible y completa regionalización de los funcionarios locales - 0 de algunos de ellos-, sino también desde la óptica de su más dudosa posible contractualización o desfuncionarización) que, junto a la existencia de unos funcionarios propios de las Corporaciones locales, que ellas mismas reclutan, es básica la permanencia de otros funcionarios, éstos con habilitación de carácter nacional, y en cuanto destinados a desempeñar unas funciones públicas necesarias, cuya necesidad se entiende presente en todos los Entes locales del Estado. Se estima, pues, que el interés a que la existencia de tales funcionarios ( $\mathrm{y}$ funciones) responde, excede del puramente local e incluso territorial, en la medida misma en que existe en todas las Corporaciones locales, pasando así a ser un interés nacional que, por ello, sólo al Estado corresponde determinar y regular. Así, el artículo 86 del Proyecto señala en su párrafo 3:

«3. Son funciones públicas necesarias en todas las Corporaciones locales, cuya resposabilidad administrativa está reservada a funcionarios con habilitación de carácter nacional: 
a) Las de Secretaría, comprensiva de la fe pública y el asesoramiento legal preceptivo.

b) El control y fiscalización interna de la gestión económicofinanciera y presupuestaria y la contabilidad, tesorería y recaudación».

Esta precisión, que supone la conservación a nivel nacional de las funciones públicas más importantes de los Entes locales, prácticamente el mantenimiento de los Cuerpos de funcionarios actualmente existentes y la imposibilidad de su regionalización, es, por otra parte, uno de los rasgos definidores de la configuración de la función pública local que el Proyecto realiza, y no deja de suscitar problemas, algunos importantes. Por de pronto, desde la perspectiva del reparto competencial entre el Estado y las Comunidades Autónomas, la cuestión de si la determinación de lo básico que al Estado corresponde - y que el Proyecto pretende - puede alterar el orden competencial establecido por la Constitución y los Estatutos (teniendo en cuenta que éstos pueden atribuir competencia exclusiva a las Comunidades Autónomas sobre el Régimen local y, por tanto, sobre sus funcionarios), o más concretamente, la de determinar cuál es el papel preciso que en ese orden de consideraciones se le reserva al legislador estatal a la hora de decidir lo que es básico.

En segundo término, el argumento de si la reserva de funciones que efectúa el artículo 86, 3, del Proyecto en favor de un grupo de funcionarios locales (con «habilitación nacional») no integrará una regulación incoherente con los principios inspiradores de la reforma global de la función pública actualmente emprendida, en gran medida soportada por la idea de puesto de trabajo, incompatible con aquella reserva.

Y, finalmente, la cuestión siempre presente en esta materia de si la existencia de unos funcionarios seleccionados en el ámbito nacional sería incompatible con el principio constitucionalmente garantizado de la autonomía local, que parece postular como una de sus más clásicas manifestaciones la disposición total sobre su propio personal.

Respecto a la primera de las cuestiones, hay que decir de entrada que no parece que la consideración como básica de la existencia de unos funcionarios seleccionados a nivel nacional pueda constitucionalmente suscitar mayores problemas competenciales con las Comunidades Autónomas, justamente por el juego especial que la 
legislación básica tiene, en cuanto uno de sus efectos característicos, aunque indirectos, es precisamente el de delimitar, terminar de perfilar, las competencias de las Comunidades Autónomas.

Es conocido, en efecto, como la noción de bases (o de normación básica en general, legislación básica, etc.); es un concepto establecido progresivamente cada vez con mayor firmeza (aun cuando no parezca una noción definitivamente cerrada) (5), en el sentido de entender por tal una noción material - no todo lo que así puede calificarse lo será; lo importante es su contenido- cuyo contenido es la regulación del interés general de la materia de que se trate, que exige, en una jurisprudencia que se remonta a la sentencia del Tribunal Constitucional de 28 de julio de 1981, una regulación nacional o general unitaria (6), que siendo ella misma expresión de una política global, su "marco" permita el desarrollo de políticas propias a las Comunidades Autónomas dentro de aquel marco (7).

Como señala la sentencia del Tribunal Constitucional de 7 de abril de 1983 (decisión que se cita ahora por referirse concretamente a la materia aquí estudiada, y de la que habremos de ocuparnos más adelante desde otra perspectiva): «Por principios, bases y directrices hay que entender los criterios generales de regulación de un sector del ordenamiento jurídico o de una materia jurídica que deben ser comunes a todo el Estado. Por ello, la mencionada idea posee un sentido positivo y otro negativo: el sentido positivo manifiesta los objetivos, fines y orientaciones generales para todo el Estado, exigidos por la unidad del mismo y por la igualdad sustancial de todos sus miembros; en sentido negativo, por la misma razón, constituye el límite dentro del cual tienen que moverse los órganos de las Comunidades Autónomas en el ejercicio de sus com-

(5) Cfr., sobre la significación de estos términos, J. SALAS: «Estatutos de Autonomía, Leyes básicas y Leyes de armonización», RAP, 100, I (1983), esp. págs. 437 y sigs.

(6) Cfr., sobre el particular, GARcía DE ENTERRIA: «El ordenamiento estatal y los ordenamientos autonómicos: sistema de relaciones», RAP, 100, I (1983), esp. págs. 234 y sigs., en un trabajo recogido también como un capítulo en la última edición del Curso de Derecho administrativo, I. La sentencia del Tribunal Constitucional de 28 de enero de 1982 dice: «... una regulación normativa uniforme y vigencia común en toda la Nación, con lo cual se asegura, en aras de intereses generales superiores a los de cada Comunidad Autónoma, un común denominador normativo...», en expresión utilizada por la doctrina (cfr., por ejemplo, GARcía DE ENTERRfa, op. cit., pág. 233). En el mismo sentido, las sentencias del Tribunal Constitucional de 8 de julio y 30 de noviembre de 1982.

(7) GaRcía dE ENTERRta, op. cit., pág. 239. Vid. la sentencia del Tribunal Constitucional de 4 de noviembre de 1982. 
petencias cuando, aun definiéndose éstas como exclusivas, la Constitución y el Estatuto las dejan así limitadas».

Dos ideas especialmente importantes a nuestros efectos es posible deducir del texto que se acaba de citar (y que podía haber sido otro, en cuanto expresa una idea consolidada). Por un lado (y prescindiendo aquí de mayores precisiones), partiendo del supuesto, a que la misma sentencia se refiere, de que «... no es fácil determinar en cada caso concreto cuáles son las bases de una determinada materia... (por lo que)... hay que considerar imposible cualquier intento de relación apriorística...», el dato de que la fijación, la concreción del impreciso contenido de las bases, es decir, la tarea del discernimiento de lo que es básico y lo que no lo es, la atribuye directamente la Constitución al Estado (8), en cuanto el artículo 149, 1, de la Constitución Española traduce las exigencias de los principios de unidad y autonomía (art. 2 de la Constitución Española) y del interés respectivo en la concreción de la autonomía, auténtica "clave explicativa» ésta de toda la operación constitucional de distribución de competencias (9). Pero además, esa atribución constitucional al Estado de la función de fijación de lo que es básico se efectúa en términos de extraordinaria amplitud, con una completa libertad (como ha señalado el Tribunal Constitucional en su sentencia de 20 de mayo de 1983) en la fijación del interés general, como, por lo demás, no podía ser de otro modo, habida cuenta de la enorme variabilidad que la determinación del interés general puede tener (10). Aunque, evidentemente, esa libertad en la fijación de las bases no puede contener, como ha señalado GARCfA DE ENTERRÍA, violación de calificaciones constitucionales, al tiempo que debe servir a valores constitucionales positivos, y cuyos límites podrá controlar ciertamente, en cada caso, el Tribunal Constitucional (11).

Por otro lado, junto a esta versión positiva de la idea de bases, la sentencia copiada más arriba se refiere también a un sentido ne-

(8) Como dice la sentencia del Tribunal Constitucional de 27 de julio de 1982: «... competencia que sólo corresponde al legislador del Estado para establecer las bases a que debe ajustarse la regulación de una determinada materia, que no son las que respecto de la misma fija, en un plano de mayor o menor abstraccion y generalidad, la propia Constitución, sino las que dentro de los amplios límites que esos principios marcan, considere más adecuado, según su propio juicio, el legislador competente, que es, sin duda alguna, el legislador estatal».

(9) S. MuÑoz Machado: Derecho público de las Comunidades Autónomas, I, Madrid, 1982, pág. 418.

(10) Como señala García de ENTERrfa, op. cit., pág. 238-239.

(11) García de EnTERrfa, op. cit., loc. cit. 
gativo de la misma, sentido cuya importancia conviene resaltar en este momento porque la tarea de determinación de las bases, que sirven a una "política global» que puede ser cambiante (en cuanto expresión de una decisión política que puede modificarse a través de la formación de nuevas mayorías parlamentarias), supone de rechazo, y esta es la idea que ahora importa destacar, la atribución a la legislación básica de una cierta función delimitadora indirecta de las competencias de las Comunidades Autónomas (12), al constituir esa legislación el "límite dentro del cual tienen que moverse los órganos de las Comunidades Autónomas en el ejercicio de sus competencias cuando, aun definiéndose éstas como exclusivas, la Constitución y el Estatuto las dejan así delimitadas" (sentencia de 7 de abril de 1983).

Pues bien, está claro, en mi opinión, que el establecimiento del carácter básico de la existencia de unos funcionarios locales nacionalmente homologados es un buen ejemplo del papel indirecto de delimitación de las competencias de las Comunidades Autónomas que a la legislación básica del Estado corresponde, lo que no tiene por qué ser entendido como violación de las normas estatutarias (cuando contemplan la calificación de la materia como competencia exclusiva) en cuanto ello es una pieza más en la delimitación del orden competencial que efectúa la Constitución y los Estatutos.

La precisión es singularmente importante, y era seguramente obligada (en el sentido en que el Proyecto lo ha hecho o en otro), no sólo porque la doctrina sentada por el Tribunal Constitucional sobre la función pública local, en las numerosas (comparativamente) ocasiones en que ha tenido ocasión de pronunciarse sobre el reparto competencial en materia de función pública local (sobre la base de la legislación preconstitucional), adolece de una confesada provisionalidad (13), sino también porque el ejercicio por el Estado de

(12) MuÑoz Machado, op. cit., I, pág. 352.

(13) Tanto el voto particular del Magistrado G6MEz-FerRer, como el del Magistrado RuBio LlORENTE, a la sentencia de 7 de abril de 1983, insisten en el carácter provisional de la solución aportada. Así, el primero: "Esta conclusión tiene un carácter provisional en tanto no se produzca la legislación básica del Estado que regule de otra forma, en su caso, el carácter del Cuerpo, delimite el ámbito de competencia de las Corporaciones locales de acuerdo con el principio de autonomía y especifique las funciones que eventualmente puedan corresponder a las Comunidades Autónomas y al Estado en relación a los Secretarios de tales Corporaciones, atendiendo a los intereses públicos en presencia y al nuevo modelo territorial introducido por la Constitución».

El segundo, por su parte: «La decisión de cómo hayan de cubrirse las Secretarías municipales, sea por funcionarios integrados en Cuerpos nacionales, como actualmente ocurre, sea mediante funcionarios propios de cada Ayuntamiento o de cualquier 
LA FUNCION PUblica EN El PROYecto DE LEY REg. De LAS BASES DEL Reg. LOCAL 439

su competencia para fijar lo que es básico (incluida esa cierta función delimitadora indirecta de las competencias de las Comunidades Autónomas) permitirá seguramente resolver de modo definitivo la actual situación de inseguridad existente sobre la función pública local (especialmente, no en cuanto a la propia existencia de funcionarios nacionales, sino en cuanto al sistema de provisión de sus puestos de trabajo, que veremos después), que se acredita (y que no ha sido resuelta ciertamente, y a lo mejor tampoco podría haberlo sido) no ya sólo por los numerosos conflictos suscitados ante el Tribunal Constitucional (así sentencias de 7 de abril de 1983, Cuerpos nacionales; 25 de octubre de 1983, ingreso en la función pública local; 27 de julio de 1982, regulación de las condiciones colectivas de trabajo, etc.), sino también por la especial virulencia de los conflictos suscitados en el País Vasco alrededor de los Secretarios de sus Corporaciones locales.

Por lo demás, en este punto el Proyecto no hace sino recoger la doctrina ya sentada por el Tribunal Constitucional en su sentencia de 7 de abril de 1983: «...tenemos que establecer que ha de considerarse como básica, dentro del ordenamiento jurídico actualmente vigente, la existencia de los Cuerpos de funcionarios citados (Secretarios, Interventores y Depositarios de Administración local) como Cuerpos de carácter nacional y la selección de los funcionarios dentro de los citados Cuerpos...».

La segunda de las cuestiones más arriba expuestas plantea si la reserva de unas determinadas funciones a unos determinados funcionarios no pudiera resultar contradictoria con alguno de los principios que nuclean la reforma global de la función pública, como, por ejemplo, el recogido en el artículo 14, 2, del Proyecto de Ley de Medidas para la Reforma de la Función Pública, cuando señala que "los puestos de trabajo serán de adscripción indistinta para todos los funcionarios incluidos en el ámbito de aplicación de esta Ley". Ello es importante porque la idea que subyace tras esta afirmación es, sin duda, uno de los impulsos capitales de la reforma emprendida, en cuanto dirigida a abrir una brecha en la tradicional estructura de los Cuerpos, tal y como hasta ahora en buena medida han venido funcionando, al venir a sustituir la idea de función reservada al Cuerpo por la idea del puesto de trabajo. Es cierto que ese pre-

otro modo que pueda imaginarse, corresponde, sin duda, a la competencia que sobre las bases del régimen jurídico de las Administraciones públicas y el régimen estatu. tario de sus funcionarios reserva al Estado en exclusividad el artículo 149, 1, 18.", de la Constitución Española». 
cepto no es de los que el artículo $1 .^{\circ}, 3$, del mismo Proyecto califica como básicos, y que cabría por ello pensar que tal idea podría no estar presente en la reforma funcionarial local, pero también lo es que el artículo 96 de esta última desmiente tal hipótesis al prever la posibilidad de que los puestos de trabajo correspondientes a los funcionarios locales, propios de la Corporación, puedan ser cubiertos por funcionarios de otras Administraciones públicas mediante el correspondiente concurso. La conclusión que es posible obtener es que la reserva expresa de unas concretas funciones a los funcionarios locales con habilitación nacional es una auténtica excepción a la presunta ruptura de los Cuerpos, que tanto ha preocupado a los miembros de los Cuerpos nacionales, lo que aparece de forma todavía más significativa tras la modificación realizada en el artículo 16 del Proyecto de Medidas para la Reforma de la Función Pública en el Congreso, de donde indirectamente se deduce que los cometidos reservados a los funcionarios locales con habilitación nacional únicamente por ellos podrán ser desempeñados. Efectivamente, el texto del Proyecto decía así: "Con el fin de lograr una mejor utilización de los recursos humanos, los puestos de trabajo de la Administración del Estado, de las Comunidades Autónomas y de la Administración local podrán ser cubiertos por funcionarios que pertenezcan a cualquiera de las Administraciones públicas, de acuerdo con lo que establezcan las relaciones de puestos de trabajo» - la fijación de las normas para cuyo establecimiento se reserva al Estado en la función pública local, por el artículo 87 del Proyecto de Ley de Bases de Régimen local-. Por el contrario, la redacción modificada del artículo 16 señala: «1. Con el fin de lograr una mejor utilización de los recursos humanos, los puestos de trabajo de la Administración del Estado y de las Comunidades Autónomas podrán ser cubiertos por funcionarios que pertenezcan a cualquiera de estas Administraciones públicas, de acuerdo con lo que establezcan las relaciones de puestos de trabajo.

2. Asimismo, los funcionarios de la Administración local podrán desempeñar puestos de trabajo en otras Corporaciones locales distintas de las de procedencia y en la Administración de su Comunidad Autónoma». Excepción esta, por lo demás, prevista con carácter general, con toda lógica, por cierto, por el párrafo siguiente al transcrito del artículo 14, 2, del Proyecto de Ley de Medidas para la Reforma de la Función Pública: «Unicamente podrán adscribirse con carácter exclusivo puestos de trabajo a funcionarios de un determi- 
nado Cuerpo o Escala cuando tal adscripción se derive necesariamente de la naturaleza y de la función a desempeñar en ellos y en tal sentido lo determine el Gobierno a propuesta del Ministro de la Presidencia". Esta disposición, que no tiene el carácter de básica para todos los funcionarios, ilustra acerca de la excepción que el Proyecto de Ley de Bases de Régimen local ha querido establecer respecto de los funcionarios con habilitación nacional, que por ello, en cuanto tienen reservadas específicamente unas determinadas funciones básicas, puede decirse que continúan formando un auténtico Cuerpo de funcionarios, disipando así los temores que los actuales miembros de los Cuerpos nacionales de Administración local han venido expresando reiteradamente, y de lo que es una muestra, por ejemplo, los numerosos y preocupados comentarios que en las Revistas dirigidas a la Administración local se han venido publicando.

Por último, la existencia de un Cuerpo de funcionarios, o de unos funcionarios "con habilitación nacional", seleccionados y reclutados (aunque con participación local, como veremos) por una instancia diversa de la propiamente municipal (y aquí podría incluirse no sólo al Estado, sino también a las Comunidades Autónomas eventualmente) pone de relieve la ya tradicional cuestión de la autonomía municipal. No es necesario insistir demasiado en que históricamente (lo que cobra ahora actualidad con la consagración constitucional de la autonomía local) la problemática del funcionariado local ha girado alrededor de este principio, en una pugna entre dos postulados opuestos dialécticamente: por un lado la autonomía local exigiría una absoluta disponibilidad de los entes locales sobre su propio personal, mientras que por otro la garantía de estabilidad en el puesto de trabajo que permitiera eliminar las arbitrariedades siempre posibles, así como la consecución de una mayor eficacia en el desarrollo de su función (y un cierto pero claro intento de control por parte del Estado), exigiría la intervención de éste en el reclutamiento de esos servidores públicos, sustituyendo de este modo el principio de la confianza por el principio de la competencia.

Este planteamiento, así esquemáticamente expuesto, está todavía hoy absolutamente presente en las reformas funcionariales que se están llevando a cabo en Francia con un sorprendente paralelismo temporal (aunque sólo temporal, porque el modelo autonómico español imposibilita en esta materia el tradicional mimetismo respec- 
to al Derecho francés) (14), aunque ciertamente hoy debe darse por resuelto a la vista del texto del Proyecto de Ley de Bases, que viene a recoger, por cierto, el impecable planteamiento de la cuestión que efectuó el voto particular del Magistrado GómEZ-FERRER a la sentencia del Tribunal Constitucional de 7 de abril de 1983, cuando, por ejemplo, señala: «...la autonomía local es compatible excepcionalmente con intervenciones puntuales de las Comunidades Autónomas o del Estado cuando la Corporación local incide en otros intereses públicos de carácter comunitario o supracomunitario, respectivamente...», desde cuya perspectiva "...la existencia del Cuerpo nacional, tal y como está básicamente configurado, responde a un interés supracomunitario, presente en todos los Municipios y Provincias españoles...», conclusión esta que si en el voto citado tiene un "carácter provisional en tanto no se produzca la legislación básica del Estado...", como ya hemos notado, dejará justamente de tenerlo en el momento en que el Proyecto comentado termine finalmente aprobándose como Ley. Porque, efectivamente, el Proyecto legítimamente encuentra que existe un interés nacional, supralocal y supracomunitario en la existencia de unos funcionarios homogéneamente formados en todo el territorio nacional, y tal afirmación, en cuanto formulada en el ejercicio del derecho (y la obligación) a la fijación de las bases que la Constitución atribuye al Estado con la amplitud que hemos visto, es difícilmente objetable, especialmente a la vista, como veremos, de las facultades que a las propias Corporaciones se reconoce de intervención en la selección de estos funcionarios.

\section{LA SELECCION, FORMACION Y PROVISION DE PUESTOS DE TRABAJO DE LOS FUNCIONARIOS CON HABILITACION NACIONAL}

Coherentemente con esta consideración básica que el Estado atribuye a la existencia en todas las Corporaciones locales de unos servidores públicos nacionales destinados a ejercer unas funciones públicas necesarias, el Proyecto establece en el artículo 93 que la selección, formación y habilitación de estos funcionarios será en todo caso estatal y uniforme, ciertamente con la finalidad de procurar una formación unitaria de los mismos que asegure un desempeño homogéneo de las funciones públicas necesarias que están llamados

(14) Cfr., por ejemplo, J. Bourdon: «Le statut général des fonctionnaires des collectivités territoriales», $A J D A, 4$ (1984), págs. 199 y sigs. 
a servir, habilitándoles para poder optar a cubrir las plazas o puestos de trabajo vacantes en cualquier Entidad local del Estado. No obstante mantenerse en manos del Estado la selección de este personal, se prevén algunas fórmulas de descentralización territorial en la realización de las promesas y de colaboración con las Comunidades Autónomas en la formación de estos funcionarios, fórmulas estas que no han dejado, sin embargo, de suscitar críticas (15).

El texto del artículo 93 del Proyecto señala:

«1. La selección, formación y habilitación de los funcionarios a que se refiere el número 3 del artículo 86 corresponde al Instituto de Estudios de Administración Local conforme a las bases y pro gramas aprobados reglamentariamente.

El Instituto de Estudios de Administración Local podrá convenir a los Institutos o Escuelas de funcionarios que establezcan las Comunidades Autónomas las fórmulas de intervención de éstos en la formación de los funcionarios que deben obtener una habilitación de carácter nacional.

Podrá asimismo descentralizarse territorialmente la realización de las pruebas de selección para el acceso a los Cursos de formación en relación con las Corporaciones de determinado nivel de población en los términos que establezca la Administración del Estado.

2. Quienes hayan obtenido la habilitación a que se refiere el número anterior ingresarán en la Administración pública local y estarán legitimados para participar en los concursos de méritos convocados para la provisión de las plazas o puestos de trabajo reservadas a estos funcionarios en las plantillas de cada Entidad local».

Con ello se establece una separación entre la titulación, la idoneidad para el desempeño del cargo (prácticamente totalmente estatal) y la provisión concreta de los puestos de trabajo, en los que se da entrada a las Corporaciones locales, volviendo en cierto modo a un sistema semejante a los tradicionales (tradicionales, por lo me. nos, hasta la completa estatalización de los Cuerpos, a partir de 1940) en buena parte de la historia de nuestro Régimen local, más conforme que el procedimiento actual con el principio de autonomía local, y que el artículo 94 del Proyecto regula minuciosamente del siguiente modo:

«1. La Administración del Estado establece las normas básicas de los concursos para la provisión de plazas reservadas a funcionarios con habilitación de carácter nacional, con inclusión de los mé-

(15) Cfr. J. M Castells: La Euskadi autonoma y los funcionarios públicos, San Sebastián, 1980, esp. pág. 103. 
ritos generales de preceptiva valoración en todo caso, cuya puntuación alcanzara el 75 por 100 del total posible conforme al baremo correspondiente. No rige esta limitación cuando la Corporación local interesada no establezca méritos específicos en razón a las características locales.

2. Las vacantes de plazas correspondientes a funcionarios con habilitación de carácter nacional serán cubiertas mediante concursos anuales convocados por la Administración del Estado.

A este efecto, las Entidades locales deberán remitir anualmente a dicha Administración relación exhaustiva de las plazas o puestos de trabajo reservados en sus plantillas a funcionarios con habilitación nacional que estén vacantes, así como, en su caso y para cada tipo de plaza o puesto de trabajo, las bases aprobadas que deban regir los concursos para su provisión, incluidos los correspondientes a baremos de méritos específicos fijados por dichas Corporaciones.

En los concursos, la Administración del Estado recibirá las solicitudes correspondientes y las remitirá a las Entidades locales interesadas.

3. Cada Corporación local, previa evaluación de los candidatos por un Tribunal nombrado en el seno de la Corporación en la forma prevenida en las bases del concurso, formulará a la Administración del Estado la correspondiente propuesta de nombramiento, que incluirá los nombres por el orden de calificación obtenida.

La Administración del Estado procederá al nombramiento del candidato con mejor calificación, según el orden de preferencia que hubiera previamente manifestado, cuando hubiera solicitado más de una plaza.

4. La toma de posesión determina la adquisición de los derechos y deberes funcionariales inherentes a la situación en activo, pasando a depender el funcionario de la correspondiente Corporación, sin perjuicio de la facultad disciplinaria de destitución del cargo y de separación definitiva del servicio, que queda reservada en todo caso a la Administración del Estado.

5. En todo caso, en esta última Administración se llevará un Registro relativo a los funcionarios locales con habilitación nacional, en el que deberán inscribirse, para su efectividad, todas las incidencias y situaciones de dichos funcionarios».

El sistema así montado, en el que quedan claramente separados la habilitación, la atribución de idoneidad para desempeñar un cargo y los concursos para la provisión de puestos de trabajo (para «la adquisición de los derechos y deberes funcionariales inherentes a la situación en activo»), es la respuesta que el legislador estatal pretende ofrecer a un tema enormemente conflictivo (particularmente en el País Vasco (16), y que dio lugar al planteamiento por esta Co-

(16) Cfr., por ejemplo, Castells, op. cit., esp. págs. 89 y sigs. 
munidad Autónoma de un conflicto positivo de competencias a propósito de a quién correspondía la titularidad para convocar y resolver los concursos de traslado de los miembros de los Cuerpos Nacionales de Administración Local, resuelto por la ya citada sentencia de 7 de abril de 1983, que muestra aquí en este punto (esto es, respecto a la provisión de puestos de trabajo más que en la existencia misma de unos funcionarios con habilitación nacional) el verdadero conflicto de fondo - aunque ello lo haya sido en aquella decisión sin suscitar un aspecto decisivo en este asunto-, cuya correcta colocación ciertamente no está, a mi juicio, en el conflicto Estado-Comunidades Autónomas, que es como fue planteado y resuelto, sino en el alcance de la intervención de las Entidades locales afectadas en el procedimiento para la provisión de puestos de trabajo en cuanto derivación del principio de autonomía local, como por lo demás observó certeramente el voto particular que el Magistrado GómEzFERRER formuló a la sentencia. Según la síntesis que el propio Tribunal Constitucional realiza, el conflicto giró «alrededor de la determinación de la autoridad a quien compete convocar y resolver en los Municipios radicados en el País Vasco los concursos para proveer plazas que corresponden a los Cuerpos nacionales de los funcionarios de la Administración local, pues se discute si en el momento actual puede convocar y resolver los concursos, en lo que concierne a Municipios radicados en el territorio de la mencionada Comunidad, el Ministerio de Administración Territorial». El núcleo central de la pretensión de los promotores del conflicto se encuentra en el artículo 149, 1, 18, de la Constitución, que reserva al Estado, como competencia exclusiva, las «bases del régimen jurídico de las Administraciones públicas y del régimen estatutario de sus funcionarios...", y en el artículo 10, apartado 4, del Estatuto de Autonomía del País Vasco, que atribuye a la Comunidad Autónoma competencia exclusiva en materia de Régimen local y en lo que concierne al Estatuto, sin perjuicio de lo establecido en el artículo 149, 1, 18, de la Constitución.

Más adelante señala la sentencia que

«...reducido a su síntesis el problema que se nos plantea, consiste en decidir si la convocatoria y la decisión de los concursos a que este asunto se refiere forman parte de las 'bases' que menciona el artículo 149, 1, 18, de la Constitución, o si, por no caer en el terreno de la limitación, entran en el artículo 10, 4, del Estatuto de Autonomía, pues, prima facie, una competencia exclusiva - sin entrar a di- 
lucidar, porque sería impertinente, lo relativo a la potestad legislativa y la de desarrollo de la legislación del Estado- conlleva los poderes de ejecución de la legislación vigente, y no ofrece duda que la convocatoria y la resolución de los concursos para cubrir plazas de funcionarios pertenece al marco de la ejecución de la normativa vigente, que sólo podrá, por tanto, corresponder al Estado si de algún modo tuviera que entenderse incardinada en las 'bases' a que se refiere el tantas veces citado artículo $149,1,18$ ».

El asunto presenta una dificultad añadida, que es uno de sus aspectos más interesantes, planteada por el hecho de que, como se observa, sobre lo que se discute no es acerca de la titularidad sobre competencias o facultades normativas, como es lo habitual, sino sobre facultades de ejecución de aquella normativa, facultades estas que, como es sabido, sólo excepcionalmente, en virtud del principio de la ejecución autonómica de la legislación del Estado (17), podrán corresponder a éste, siendo ordinariamente su ejercicio, con carácter general, competencia de las Comunidades Autónomas.

Así planteada la cuestión, la solución ofrecida mayoritariamente por el Tribunal Constitucional consiste en entender que facultades de ejecución, como son la convocatoria y resolución de concursos para la provisión de las plazas de referencia, también pueden ser consideradas como integrantes de la noción de bases, en cuanto «todo aquello que sea preciso para la preservación de la normativa de una institución considerada como básica debe ser entendido asimismo como básico por vía de consecuencia o de conexión", de tal modo que «si hemos considerado que es básica en el ordenamiento jurídico vigente la existencia de un Cuerpo de funcionarios de alta cualificación, tiene que ser cierto que ha de poseer la misma connotación todo aquello que preserve la existencia de ese Cuerpo, y ello permitirá proscribir lo que lo haga desaparecer o lo menoscabe». En consecuencia, y puesto que quien determina lo que es básico es el Estado, el Tribunal Constitucional resuelve el conflicto en favor del Estado, aun cuando el Magistrado Rubio Llorente formuló un voto particular discrepando en el fallo, al que se adhirió el Magistrado TOMÁs Y VALIENTE, contestando frontalmente la solución mayoritaria: "Lo que no cabe hacer — señala este voto particular-, sino en supuestos muy limitados y excepcionales, es admitir que la competencia sobre bases o sobre legislación básica incluye también

(17) Cfr. GARcía DB ENTERRfa: La ejecución autonómica de la legislación del Estado, Madrid, 1983. 
la competencia de simple ejecución. Puede ser ello así cuando el acto de ejecución afecta directamente a intereses de diversas Comunidades Autónomas (sentencias núms. 1/1982 y 44/1982) o la ejecución comporta por necesidad intrínseca de la materia básica en cuestión márgenes tan amplios de discrecionalidad que sólo puede ser encomendada a instancias que no tienen a su cuidado intereses peculiares distintos de los puramente generales (sentencias números $1 / 1982,8 / 1982$ y 44/1982), o bien, pero esta es una excepción que juega en ambos sentidos, cuando una situación de urgencia obliga al poder público que ha tenido conocimiento de la misma a actuar directamente para evitar daños irreparables (sentencia número 16/1982). Es claro que en el presente asunto no se da ninguno de estos supuestos ni otro alguno que pudiera llevar a una conclusión análoga", por lo que estima que el fallo debería haber reconocido la competencia en favor del País Vasco.

El desarrollo posterior de la jurisprudencia constitucional ha venido a reforzar la tesis formulada (aunque imperfectamente) por la sentencia, como ha puesto de relieve GARCía DE ENTERRÍA, viniendo así a tener el concepto de "bases» un nuevo desarrollo inicialmente impensado (18), que permite al Estado caracterizar con esta nota de básicas competencias de ejecución.

De este modo, la regulación que el Proyecto establece respecto a los concursos para la provisión de plazas encuentra cobertura constitucional desde el punto de vista del reparto competencial con las Comunidades Autónomas, al resultar posible introducir en una Ley básica normaciones detalladas que incluyan facultades de ejecución que el Estado se reserva por entender que efectivamente son «básicas». La última palabra habrá de tenerla, desde luego, el Tribunal Constitucional, pero teniendo en cuenta la amplia libertad que tiene el legislador estatal para establecer las bases, habiendo señalado explícitamente el Tribunal Constitucional con anterioridad a esta sentencia (sentencias de 28 de abril y 30 de mayo de 1982) que "la competencia estatal para establecer bases puede implicar la posible atribución de facultades concretas a la Administración del Estado

(18) Se muestra crítico, sobre el particular, al comentar esta sentencia, J. EsTEve: «Bases estatales y competencias de ejecución», REDA, 39 (1983), pág. 621, que no ha podido manejar, lógicamente, las variaciones introducidas por GARcía DE ENTERRIA respecto a esta cuestión en el trabajo más arriba citado, en relación con la formulación que anteriormente había efectuado en $\mathrm{La}$ ejecución autonómica de la legislación del Estado, cit., esp. págs. 66 y sigs. Cfr. también S. MuÑoz Machado: Derecho público de las Comunidades Autonomas, I, cit., pág. 417, y J. SALAs: Estatutos de Autonomía..., cit., págs. 438 y sigs. 
en determinadas materias si así viene exigido por la naturaleza de éstas y por la necesaria garantía de intereses supracomunitarios», intereses supracomunitarios cuya consideración no es difícil aventurar que está en el origen de la solución aportada en este punto por el Proyecto de Bases de Régimen local.

Ahora bien, tanto la sentencia a que me refiero como el voto particular expuesto han centrado la cuestión exclusivamente en el aspecto indicado, desconociendo con ello otra faceta verdaderamente importante en la regulación de esta materia, como es el juego del principio de autonomía local. Ello, sin embargo, como es lógico, no le ha pasado desapercibido al autor del Proyecto, como tampoco al Magistrado GómEz-FERRER, que formuló a su vez otro voto particular, coincidente éste en cuanto fallo, discrepando únicamente en cuanto a la fundamentación, y cuyas acertadas consideraciones vale la pena transcribir en cuanto contribuyen, sin duda, a situar adecuadamente el Proyecto de Ley de Bases, que no hace sino recoger las sugerencias allí expuestas:

«1. El parecer mayoritario no toma en consideración un aspecto que, a mi juicio, es de capital importancia, como es el relativo al principio de autonomía de los Municipios y Provincias, consagrado por el artículo 137 de la Constitución, para la gestión de sus respectivos intereses, principio que, con carácter general y la reserva de ulteriores precisiones, excluye las medidas de tutela sobre las Corporaciones locales.

2. No obstante la afirmación anterior, de carácter general, debe recordarse ahora que la autonomía local es compatible, excepcionalmente, con intervenciones puntuales de las Comunidades Autónomas o del Estado cuando la Corporación local incide en otros intereses públicos de carácter comunitario o supracomunitario respectivamente, según puso de manifiesto el Tribunal en la sentencia de 2 de febrero de 1981 (recurso de inconstitucionalidad 186/1980, Fund. Jur. 3.', Boletin Oficial del Estado de 24 de febrero): El determinar la posible competencia de las Comunidades Autónomas y del Estado en estos casos ha de ser justamente una parte del contenido de la Ley básica en materia de Régimen local que ha de dictar el Estado, pues como indicó también el Tribunal en la sentencia de 28 de julio de 1981 (recurso de inconstitucionalidad 40/1981, Fund. Jur. 5 y 6, Boletin Oficial del Estado de 13 de agosto): La Constitución prefigura una distribución territorial de los poderes basada en el principio de autonomía que es contrario al de centralización antes imperante, por lo que las bases de la legislación preconstitucional no se ajustan al nuevo modelo del Estado, de ahi que resulte especialmente necesaria una legislación básica posconstitucional que al sentar las bases del régimen jurídico de la Administración local delimite con exactitud el 
LA FUNCION PUBLICA EN EL PROYECTO DE LEY REg. DE LAS BASES DEL REg. LOCAL 449

alcance del principio de autonomía y precisamente el ámbito de posible actuación de las Comunidades Autónomas y del Estado en relación a las Corporaciones locales.

4. ... La conclusión en el momento actual ha de ser que la competencia controvertida corresponde al Estado, ya que la existencia del Cuerpo nacional - tal y como está básicamente configuradoresponde a un interés supracomunitario, presente en todos los $\mathrm{Mu}$ nicipios y Provincias españoles. Esta conclusión tiene un carácter provisional en tanto no se produzca la legislación básica del Estado que regule de otra forma, en su caso, el carácter del Cuerpo, delimite el ámbito de competencia de las Corporaciones locales de acuerdo con el principio de autonomía y especifique las funciones que eventualmente puedan corresponder a las Comunidades Autónomas y al Estado en relación a los Secretarios de tales Corporaciones, atendiendo a los intereses públicos en presencia y al nuevo modelo territorial introducido por la Constitución".

Ello es precisamente lo que en los términos más arriba transcritos ha hecho efectivamente el Proyecto.

Desde esta perspectiva de la autonomía local cabría hacer algunas consideraciones sobre la fórmula ofrecida por el Proyecto (sin entrar en mayores pormenorizaciones), de la que hay que decir, desde luego, que es una fórmula que permite dar entrada a los intereses de las Corporaciones locales afectadas, y en este sentido garantizar la autonomía local, reforzándola notablemente incluso respecto a la situación actual.

Ahora bien, en cuanto se trata de una fórmula que de algún modo y con matizaciones supone una vuelta a los sistemas tradicionales de provisión de puestos de trabajo entre funcionarios de los Cuerpos nacionales (tradicionales por lo menos hasta la completa estatización de estos que se produce a partir de 1940, momento en el que en un proceso conocido se produce la disociación completa de la relación orgánica y la de servicio entre el Estado y las Corporaciones locales, tan característica de estos funcionarios), tal vez no fuera ocioso recordar el juego de estos sistemas en los que la intervención de los Entes locales alcanzaba el nombramiento (no a la selección), y por tanto a ellos correspondía también la competencia para proceder a la destitución del cargo de los correspondientes funcionarios (no la separación del servicio), en un juego del principio de autonomía local que no puede considerarse desde luego excesivo si se le somete a los debidos temperamentos.

Sin pretender hacer ahora y aquí una historia de los sistemas de provisión de plazas de los funcionarios citados, sí puede señalarse, 
en efecto, cómo fue el Reglamento de 11 de diciembre de 1900, de «Secretarios de Diputación y Contadores provinciales y municipales», el que "puso sobre la mesa la gran cuestión de conectar la autonomía reconocida en la Ley con la necesidad imperiosa de exigir condiciones de capacidad y aptitud a determinados funcionarios de las Corporaciones locales» (19), estableciendo (20) por primera vez la separación presente ahora en el Proyecto de Ley de Bases de Régimen local entre el título de aptitud, que queda estatizado, en cuanto la idoneidad para el desempeño de las funciones de Secretario la otorga el Estado, y el nombramiento para la provisión de puestos de trabajo en Corporaciones concretas, que permanece en manos de las Corporaciones respectivas, aun cuando sea de destacar que a esta facultad de las Entidades locales no se le establece condicionamientos de ningún tipo respecto a la elección del correspondiente funcionario, lo que quizá resultara hoy excesivo en función de la tutela de los intereses generales que el Estado tiene encomendados.

La legislación surgida de los Estatutos de Calvo Sotelo, que vino a suponer «la coronación de las apetencias de los Cuerpos de funcionarios a que nos venimos refiriendo al dotarlos de estabilidad y propias atribuciones» (21) y que fusionó en un solo Cuerpo los de Secretarios de Diputaciones y de Municipios, regula la provisión de puestos de trabajo en la misma línea que la normativa anterior, previo concurso, por las Corporaciones locales, distinguiéndose del mismo modo entre el ingreso en el Cuerpo y el nombramiento a destino concreto como fases independientes, aunque variando la intervención estatal según se tratara de Ayuntamientos o Diputaciones, siendo mayor en éstas, en donde el Ministerio de la Gobernación podía resolver sustitutoriamente el concurso si la Corporación provincial correspondiente no lo hubiera hecho en el plazo de treinta dias. Por otra parte, el Reglamento municipal de 23 de agosto de 1924 autorizaba la imposición de la sanción disciplinaria de destitución a los

(19) J. A. García-Trevijano: Tratado de Derecho administrativo, t. III, vol. II, página 108 .

(20) Junto con el Reglamento -el primero- de Secretarios de Ayuntamiento de 14 de junio de 1905, derogado en 1907, y el provisional de 24 de agosto de 1916, que puso en vigor un Proyecto de 1902, el Reglamento Orgánico del Cuerpo de Secretarios de Ayuntamiento, impulsados todos ellos por el mismo aliento corporativo a que se hace alusión en el texto. Sobre la problemática en el País Vasco, en donde habitualmente se excepcionaron, 0 sencillamente, no se aplicaron los Reglamentos estatales, cfr. I. M. CAStells: La Euskadi autónoma y los funcionarios públicos, cit., especialmente págs. 11 y sigs.

(21) García-Trevijano: Tratado..., cit., III, II, pág. 1098. 
Ayuntamientos (en lógica correspondencia con la competencia para su nombramiento), pero no (también con toda lógica) la sanción de separación del servicio, reservada al Estado, por diferencia con la regulación que la reforma pretende incorporar, en donde, permaneciendo en las respectivas Corporaciones el grueso de las competencias disciplinarias (que habrán de regularse con respecto de las bases fijadas por el art. 30 del Proyecto de Ley de Medidas para la Reforma de la Función Pública), el Estado se reserva en todo caso «la facultad disciplinaria de destitución del cargo y de separación definitiva del servicio".

Conviene notar, por último, que todo este sistema tradicional entre nosotros contrasta vivamente con la trayectoria seguida en Francia para funcionarios equivalentes, en donde el principio de autonomía respecto al nombramiento y disposición sobre los funcionarios locales se ha impuesto desde siempre de forma absoluta, de tal modo que los Secretarios, por ejemplo, han sido habitualmente discrecionalmente nombrados por las Corporaciones respectivas, hasta el punto de que en la actual reforma emprendida en Francia, una de cuyas características es precisamente una fortísima tendencia a la estatalización de todo el funcionariado local, siguen siendo de nombramiento discrecional (no adquiriendo naturalmente la condición de funcionarios) los Secretarios de Corporaciones mayores de 80.000 habitantes y los Secretarios Generales adjuntos de poblaciones mayores de 150.000 habitantes. Ello, desde luego, no es sino una fase en un proceso burocratizador de la función de Secretario, cuya solución legal en la reciente Ley de 26 de enero de 1984 ha sido criticada por discriminatoria (22).

\section{LOS FUNCIONARIOS PROPIOS DE LAS CORPORACIONES LOCALES}

Junto a los funcionarios con habilitación nacional, el Proyecto regula también el estatus básico de los funcionarios propios de las Corporaciones locales, a los que dedica también varios preceptos, dejando lógicamente muchas más posibilidades de intervención a la legislación de desarrollo de las Comunidades Autónomas y fijando en un ámbito mucho mayor la disponibilidad autonómica local sobre sus propios funcionarios.

(22) Cfr. J. Bourdon: Le statut général.... cit., pág. 209. 
Así los artículos 95, 96 y 97 señalan:

Artículo 95.-«1. Es de competencia de cada Corporación local la selección de los funcionarios no comprendidos en el número 3 del artículo 86.

2. Corresponde, no obstante, a la Administración del Estado establecer reglamentariamente:

a) Las reglas básicas y los programas mínimos a que debe ajustarse el procedimiento de selección y formación de tales funcionarios.

b) Los títulos académicos requeridos para tomar parte en las pruebas selectivas, así como los diplomas expedidos por el Instituto de Estudios de Administración Local o por los Institutos o Escuelas de funcionarios establecidos por las Comunidades Autónomas, complementairos de los títulos académicos, que puedan exigirse para participar en las mismas».

Artículo 96.- "Los puestos de trabajo vacantes que deban ser cubiertos por los funcionarios a que se refiere el artículo anterior se proveerán normalmente por concurso de méritos entre funcionarios que pertenezcan a cualquiera de las Administraciones públicas; no obstante, aquellos puestos en que así esté establecido en la relación de puestos de trabajo podrán ser provistos mediante libre designación en convocatoria pública, asimismo entre funcionarios.

Serán de aplicación en todo caso las normas que regulen estos procedimientos en todas las Administraciones públicas».

Artículo 97.- «Tanto las pruebas para la selección de funcionarios como los concursos para la provisión de puestos de trabajo a que se refiere el presente capítulo se regirán por las bases que apruebe el Pleno de la Corporación, y serán resueltos por éste, motivadamente, previa propuesta del Tribunal designado al efecto».

Esta regulación del Proyecto es necesario conectarla con otras disposiciones, como el artículo 14 del Proyecto de Ley de Medidas para la Reforma de la Función Pública o como los artículos 84 y 96 del propio Proyecto de Ley de Bases, en la medida en que en esos preceptos se contienen disposiciones que pueden situar la función pública, en este caso la local, en un camino de racionalización cierta. Es verdad que el cumplimiento de la idea que preside esos preceptos dependerá en buena medida, en cuanto a su eficacia real, de lo que establezcan las normas de desarrollo, pero también lo es que en principio la necesidad de establecer una relación de puestos de trabajo, su descripción y clasificación es una tarea previa e impres- 
cindible, adecuada sin duda a la consecución de aquella finalidad racionalizadora. Ello supone en términos generales, sin duda, un ataque directo a la actual estructura de la función pública apoyada en los Cuerpos de funcionarios, lo que si ciertamente puede plantear problemas en el ámbito de la función pública estatal, no parece que sea especialmente grave, sino todo lo contrario, en mi opinión, respecto de la función pública local, en donde la estructura corporativa respecto de los funcionarios propios de las Entidades locales no ha sido afortunadamente enlazada. Ello es afortunado en la medida en que la puesta en práctica del nuevo modelo territorial del Estado hubiera obligado a desmontar esa posible burocracia estatalizada, si hubiera conseguido finalmente consolidarse, en función de las amplias competencias de las Comunidades Autónomas en esta materia, que los textos transcritos más arriba ponen de relieve.

Hay que decir, sin embargo, que ese proceso de estatalización de la función pública local había ya comenzado y dado pasos importantes, cuya línea de tendencia viene a ser ahora truncada. Así, por ejemplo, la Base 40 de la Ley de 19 de noviembre de 1975 (y el Decreto de 6 de octubre de 1977, art. 104) preveía ya la creación de Cuerpos nacionales de funcionarios locales (23). Esta línea de tendencia, de no producirse la formidable innovación introducida por la Constitución en la distribución territorial del poder, no parece dudoso que hubiera culminado en la creación de un Cuerpo nacional de funcionarios locales, cuya estatización "y su traslado por concurso entre Entes locales suprimiría de raíz la autonomía», como

(23) El apartado 4 de la Base 40 señalaba: «Se crearán aquellos Cuerpos nacionales de funcionarios de Administración local que así lo exijan las necesidades funcionales de las Entidades locales.

El Gobierno, mediante el establecimiento de las categorías y clases que se precisen, y teniendo en cuenta las pruebas selectivas para su acceso, regulará la integración de los actuales funcionarios de las Entidades locales en los correspondientes Cuerpos nacionales de nueva creación».

El artículo 104 del texto articulado parcial de esa Ley dice: «1. El Gobierno, a propuesta del Ministro del Interior, previos los trámites de información pública, de informe de la Comisión Superior de Personal y del Ministerio de Hacienda y del dictamen del Consejo de Estado, podrá crear otros Cuerpos nacionales de funcionarios de la Administración local, cuando así lo exijan las necesidades funcionales de las Entidades locales.

2. La creación de un Cuerpo nacional llevará inherente:

a) La organización y realización por el Instituto de Estudios de Administración Local de las pruebas selectivas y subsiguientes cursos de habilitación.

b) La estructuración del Cuerpo, en su caso, en diversas clases o categorías, cuando las mismas sean aconsejables por razones de la naturaleza de las funciones a desempeñar en las distintas clases de Corporaciones.

c) La provisión de puestos de trabajo vacantes en las Corporaciones locales se hará mediante concurso convocado y resuelto por la Dirección General de Adminis- 
hace ya bastantes años había señalado Garcia-TreviJano (24). Y como por cierto ha ocurrido ya en Francia con las recientes reformas de la función pública.

La no creación de Cuerpos nacionales para este tipo de funcionarios no quiere decir, sin embargo, que su carrera haya de quedar necesariamente circunscrita a una sola Corporación, situación esta especialmente delicada en los pequeños Municipios, cuya ruptura integra una aspiración absolutamente legítima y que sin duda estaba en la base de la reivindicación de la creación de un Cuerpo de funcionarios estatizado. Este es el tema de lo que el Proyecto de Ley de Bases de Régimen local y el de Medidas para la Reforma de la Función Pública denominan "movilidad» de los funcionarios, e integra un argumento de singular importancia en esta materia. El artículo 96 de aquél determina, como ya hemos visto, que los concursos de méritos (que junto con la posibilidad de libre designación integran los sistemas de provisión de plazas - a diferencia de lo que ocurre con los funcionarios con habilitación nacional, cuyas plazas únicamente se cubren por concurso-) estarán abiertos a funcionarios «que pertenezcan a cualquiera de las Administraciones públicas», lo que no sitúa adecuadamente el problema a que nos referimos. La cuestión de si los funcionarios propios de las Corporaciones locales pueden ocupar puestos de trabajo fuera de su Corporación local viene resuelta en el Proyecto de Ley de Medidas para la Reforma de la Función Pública, cuyo artículo 16, de carácter básico, establece que «los funcionarios de la Administración local podrán desempeñar puestos de trabajo en otras Corporaciones locales distintas de las de procedencia y en la Administración de su Comunidad Autónoma», modificando así el texto del Proyecto, que preveía la posibilidad de ocupar puestos de trabajo también en la Administración del Estado. Desde esta perspectiva, si el Proyecto de Ley de Bases no modifica su texto, resultará que los puestos de trabajo de los funcionarios propios de las Corporaciones locales podrán ser desempeñados por funcionarios pertenecientes a cualquier Administración pública, mientras que aquéllos únicamente podrán desempe-

tración Local, de acuerdo con la tabla de méritos que reglamentariamente se establezcan.

d) Deberá regularse la integración de los funcionarios ya existentes en cada una de las clases o categorías del Cuerpo o Cuerpos nacionales que se creen, para lo que podrán establecerse pruebas complementarias.

(24) García-Trevijano: Tratado..., cit., III, II, pág. 1115. 
ñarlos en la Administración de las Comunidades Autónomas (u otras Administraciones locales), lo que con todo no es desde luego poco.

\section{DISPOSICIONES COMUNES A LOS FUNCIONARIOS DE CARRERA}

Bajo el epígrafe que se acaba de reseñar, el Proyecto regula una serie de cuestiones diversas, algunas de las cuales ya hemos visto (artículo 86), entre las que se encuentran la confección de las relaciones de puestos de trabajo (25), el tema de las retribuciones y la jornada de trabajo (26), o la participación de los funcionarios en la determinación de sus condiciones de trabajo (art. 90), junto con una referencia al Instituto de Estudios de Administración Local (27) y la regulación de la publicidad (nacional) de los anuncios de las convocatorias de acceso a la función pública local y de concursos para la provisión de puestos de trabajo (art. 92). Precisamente esta última cuestión, junto con el tema de la participación de los funcionarios en la fijación de sus condiciones de trabajo, integran, sin duda, los argumentos más importantes en esta materia y que requieren por ello algún comentario.

Pero antes tal vez convenga hacer alusión a la previsión del artículo 85 del Proyecto, que reiterando las reglas que la Constitución

(25) Si bien el Proyecto concede intervención a las Comunidades Autónomas, a través de las normas de desarrollo, en la determinación de qué funciones pueden ser consideradas como públicas $\mathrm{y}$, en consecuencia, deberán ser desempeñadas por funcionarios, la formación de la relación de puestos de trabajo reservados a funcionarios corresponde lógicamente a cada una de las Corporaciones locales, aunque el Estado se reserva el establecimiento de las normas con arreglo a las cuales hayan de confeccionarse la relación de puestos de trabajo, la descripción de puestos tipo y las condiciones requeridas para su creación, si bien se da entrada a las Comunidades Autónomas a la hora de regular las vicisitudes de la carrera administrativa, reservándose únicamente el Estado, al respecto, las normas básicas, «especialmente por lo que se refiere a la promoción de los funcionarios a niveles y grupos superiores» (artículo 87 del Proyecto).

(26) El tema retributivo, lo mismo que la jornada de trabajo, se aborda en el Proyecto desde la perspectiva de la homogeneidad con el resto de los funcionarios públicos, aunque sin perjuicio de reconocer a las Corporaciones locales cierta autonomía en cuanto a la fijación de las retribuciones complementarias, que deberán moverse entre unos máximos y unos mínimos fijados, no obstante, por el Estado, aunque ateniéndose «a la estructura y criterios de valoración objetiva de los del resto de los funcionarios públicos» (art. 38). Respecto a la jornada de trabajo, el artículo 89 dice que «la jornada de trabajo de los funcionarios de la Administración local será la misma que se fije para los funcionarios de la Administración civil del Estado.

Se les aplicarán las mismas normas sobre equivalencias y reducciones de jornadan.

(27) El artículo 91 del Proyecto señala: «El Instituto de Estudios de Administración Local desarrollará cursos de perfeccionamiento, especialización y promoción para los funcionarios al servicio de las Entidades locales, y colaborará en dichas funciones con los Institutos o Escuelas de funcionarios de las Comunidades Autónomas». 
establece respecto a la selección de todo el personal al servicio de la Administración garantiza que todo el dependiente (funcionario o no) de las Corporaciones locales sea seleccionado por medio de la correspondiente oferta de empleo público y a través de convocatoria pública, justamente para hacer efectivos los principios constitucionales de publicidad, mérito y capacidad, así como la neutralidad e independendencia de los funcionarios. Este precepto señala:

«1. Las Corporaciones locales formularán públicamente su oferta de empleo ajustándose a los criterios fijados en la normativa básica estatal.

2. La selección de todo el personal funcionario y laboral debe realizarse, de acuerdo con la oferta de empleo público, mediante convocatoria pública y a través del sistema de concurso, oposición o concurso-oposición libre en los que se garanticen en todo caso los principios constitucionales de publicidad, mérito y capacidad».

Como se ha apuntado, en la línea de equiparación expresa de las condiciones de trabajo de los funcionarios locales al resto de los funiconarios, presenta un gran interés la previsión, que realiza el artículo 90 del Proyecto, de que «la participación de los funcionarios a través de sus organizaciones sindicales en la determinación de sus condiciones de empleo será la establecida con carácter general para todas las Administraciones públicas en el Estatuto Básico de la Función Pública». Es ciertamente una compleja problemática la que subyace bajo este precepto, que a pesar de su importancia aquí únicamente puede ser abordada lateralmente y en sus trazos gruesos. Hay que decir, por de pronto, que la precisión era necesaria por dos razones: por un lado, porque el Tribunal Constitucional ha tenido ya ocasión de pronunciarse al respecto en su sentencia de 27 de julio de 1982, declarando la incompetencia del Gobierno vasco para la regulación colectiva de las condiciones de trabajo en la Administración local, y, por otro lado, porque el Proyecto de Ley de Medidas para la Reforma de la Función Pública no considera básico - y por tanto aplicable a todas las Administraciones públicasla regulación que establece respecto a esta cuestión de la negociación colectiva de los funcionarios.

La sentencia del Tribunal Constitucional citada parte de la idea, ya apuntada, de que la Constitución mantiene la distinción, existente ya en la legislación preconstitucional, entre personal funcionario y personal laboral de las Administraciones públicas, con la diferente naturaleza jurídica de su relación, de tal modo que la negociación 
colectiva únicamente le resulta posible a este último tipo de personal. Si bien es cierto - continuando con la línea argumental del Tribunal Constitucional- que puede observarse una tendencia favorable a la intervención de las representaciones funcionariales en la determinación de las condiciones de empleo, también es verdad que ello no supone una auténtica negociación colectiva, tal y como aparece en el artículo 37 de la Constitución española, porque su resultado carece de vinculación alguna para los poderes públicos, no pudiendo tampoco entenderse que del derecho de sindicación de los funcionarios públicos pueda desprenderse necesariamente el derecho de negociación colectiva, y menos con eficacia vinculante para la Administración, "haciendo perder la supremacía a la Administración con graves consecuencias». Por el contrario, «el legislador puede optar por diferentes medidas que resuelvan la participación de los órganos representativos de los funcionarios en la fijación de las condiciones de empleo, como lo demuestra el Derecho comparado, en que por regla generalizada se necesita de una norma estatal o de una autoridad superior que apruebe el convenio".

Esta posición del Tribunal Constitucional, sintéticamente expuesta, ha sido criticada recientemente por algún autor (28), calificándola de conservadora, por entender que, al contrario de lo que opina el Tribunal Constitucional, el derecho de sindicación y de huelga, su reconocimiento constitucional, lleva como consecuencia necesaria el reconocimiento del derecho a la negociación colectiva, pronunciándose en consecuencia lógica por la completa contractualización de la relación de servicio de los funcionarios.

Ciertamente que esta posición crítica es sugerente, en la línea de la «laboralización» de la función pública, y probablemente ha podido tener alguna influencia en la redacción que el Proyecto de Ley de Medidas para la Reforma de la Función Pública ha dado al tema en el artículo $2 .^{\circ}$, pero también lo es que ese texto no viene a recoger enteramente aquella tesis ni desvirtuar la opción constitucional por el sistema funcionarial como criterio general entre la Administración y los servidores públicos. Establece, por el contrario, una diferencia capital, en la línea de lo apuntado por el Tribunal Constitucional y en el mantenimiento de la opción funcionarial contenida en la Constitución, entre la fijación de las condiciones de empleo de los funcionarios y del personal sometido al Derecho laboral, consistente

(28) Ortega: Los derechos sindicales de los funcionarios públicos, cit., esp. páginas 318 y sigs. 
en que mientras en este último caso las negociaciones colectivas conducen directamente a un pacto, a un auténtico convenio colectivo, en una remisión neta a las normas laborales al respecto, la intervención del personal funcionario en la fijación de sus condiciones de trabajo se mueve en un plano mucho más modesto, en cuanto esa negociación no desemboca en un convenio colectivo, sino que necesita, en caso de acuerdo, una aprobación expresa y formal del mismo por el Gobierno como requisito nada menos que de «validez» y de "eficacia» del resultado alcanzado, al tiempo que si no hay acuerdo en la negociación es el propio Gobierno quien fija unilateralmente las condiciones de empleo de los funcionarios públicos (29).

Esta normativa, que el Proyecto de Ley citado no considera básica (30), es llamada, sin embargo, en su aplicación para las Corporaciones locales por el artículo 90 del Proyecto de Ley de Bases de Régimen local, que significativamente, en el mismo sentido, habla de participación de los funcionarios en la determinación de sus. condiciones de empleo a través de sus organizaciones sindicales, lo que obviamente remite al reconocimiento del derecho constitucional de sindicación. En definitiva, esta regulación en el ámbito local vendrá a ser la misma, en sus términos generales, que aquélla, incorporando su problemática característica, sin perjuicio del desarro-

(29) El artículo 2, 2, b), del texto aprobado por el Congreso, que refunde los apartados b) y c) del Proyecto enviado por el Gobierno, señala: «2. Corresponde, en particular, al Gobierno: ...b) Establecer las instrucciones a que deberán atenerse los representantes de la Administración del Estado cuando proceda la negociación con la representación sindical de los funcionarios públicos de sus condiciones de empleo, así como dar validez y eficacia a los acuerdos alcanzados mediante su aprobación expresa y formal, y establecer las condiciones de empleo para los casos en que no se produzca acuerdo en la negociación».

Puede ser de interés recordar aquí cómo la situación es semejante a la introducida. por la reforma francesa, a la que ya hemos hecho referencia. En el artículo 8, apartado $2^{\circ}$, de la Ley de 13 de julio de 1983 , que regula los derechos y obligaciones sindicales, tienen capacidad para desarrollar negociaciones previas a la determinación de la evolución de las retribuciones, con el Gobierno, en el ámbito nacional, y con las diferentes autoridades administrativas, en sus distintos niveles, respecto a cuestiones: relativas a las condiciones y a la organización del trabajo. De esta disposición se ha. podido decir que carece de efectos prácticos, respondiendo su redacción a un compromiso adquirido en el curso de la concertación con las organizaciones sindicales, que hubieran deseado instituir en la función pública procedimientos análogos a la obligación de negociar establecida en el Code du Travail (Gaborit, op. cit., pág. 187). Este mismo autor - Profesor de Ciencia Política - señala que este procedimiento, propio. del Derecho laboral, no resulta trasladable a la función pública, cuyos servidores, a diferencia de los trabajadores cubiertos por el Code du Travail, se encuentran en una situación estatutaria y reglamentaria, concluyendo que parece que el Gobierno lo que ha querido ha sido dar una satisfacción puramente simbólica a las organizaciones sindicales, pero cuya capacidad de negociación ofrecida a los sindicatos no parece que deba provocar consecuencias novedosas sobre el Derecho de la función pública.

(30) De acuerdo con el artículo 1, 3, del Proyecto. 
LA FUNCION PUBliCA EN EL PROYECTO DE LEY REG. DE LAS BASES DEL REg. LOCAL 459

llo que de las bases estatales puedan hacer las Comunidades Autónomas para regular sus especialidades.

El otro argumento destacable, a que antes nos referíamos, era el relativo a la publicidad (nacional) de las convocatorias de acceso a la función pública local, tanto de ingreso en la misma como de provisión de puestos de trabajo, que, referido a todos los funcionarios locales, regula el artículo 92 del Proyecto del siguiento modo:

aLos anuncios de convocatorias de pruebas de acceso a la función pública local y de concursos para la provisión de puestos de trabajo deberán publicarse en el Boletín Oficial del Estado.

Las bases se publicarán en el Boletín Oficial de la Provincia, salvo las relativas a las convocatorias de pruebas selectivas para la obtención de la habilitación de carácter nacional, que se publicarán en el Boletín Oficial del Estado».

La singularidad de este texto radica en que con él se viene a rectificar la doctrina sentada por el Tribunal Constitucional en su sentencia de 25 de octubre de 1983 (legítimamente, por cierto), con ocasión de la resolución de un conflicto positivo de competencias suscitado por el Gobierno vasco contra el Real Decreto de 2 de abril de 1982, sobre procedimiento de ingreso en la función pública local, y cuyo proceso se nucleó, en lo que nos importa, alrededor de dos cuestiones: la composición de los Tribunales y la publicidad de la convocatoria para el ingreso en la función pública local (con exclusión de los Cuerpos nacionales). La decisión del Tribunal Constitucional estableció que la titularidad de la competencia controvertida correspondía al País Vasco, respecto de la Administración local del mismo, aunque no estima la pretensión de nulidad del Real Decreto, entendiendo que puede servir como derecho supletorio en el País Vasco, sobre la base de la consideración capital de que en la interpretación que el propio Tribunal Constitucional ofrece, el Reai Decreto no contiene «contenidos básicos reservados a la competencia exclusiva del Estado». Esa interpretación, respecto a la publicidad de las convocatorias, que es lo que ahora nos interesa (el tema de los Tribunales, su composición concreta, no se aborda con el carácter de básico por el Proyecto de Ley), es la siguiente: «... La publicidad es un elemento indispensable de exteriorización de la convocatoria. Pero la instrumentación única de una publicidad que como modelo uniforme y general se imponga a todas las Administraciones agotaría, por lo demás, una parcela, dentro de la función pú- 
blica local, en la que, en principio, concurren competencias normativas del Estado y del País Vasco».

Sin perjuicio de que el tema de la función pública local pueda tener algunos matices peculiares en el País Vasco, en función de los «derechos históricos» (31), asunto al que no hace alusión, por cierto, la sentencia, es lo cierto que la argumentación sostenida por el Tribunal Constitucional es, si se pretende de valor general (en cuanto a diferencia de la sentencia de 7 de abril de 1983 sobre Cuerpos nacionales, no precisa el carácter de provisionalidad del enjuiciamiento que realiza -al operar sobre normas o preconstituciones o no dictadas con el carácter de básicas-, enjuiciamiento que podría variar si el Estado hace uso de su competencia constitucional para dictar las normas básicas en la materia), desacertada y errónea, en el sentido de que su solución, pretendiendo eliminar un conflicto, puede generar una cascada de litigios, nada conforme con la función pacificadora del Tribunal, y sin que, por lo demás, pueda impedir la previsión de una solución diferente a la hora de la fijación de lo básico por el Estado.

En efecto, no es difícil aventurar que el legislador estatal actúa correcta y legítimamente (con respecto a las reglas que de acuerdo con la Constitución y los Estatutos regulan el reparto competencial en la materia) cuando entiende que la publicidad nacional de las convocatorias, a que se refiere el artículo 92 del Proyecto, es un elemento básico de la función pública local. No es sólo que la facultad de la determinación de lo básico que al Estado le corresponde le consentiría aportar una regulación (tan mínima, por cierto) como la efectuada, que no afecta en absoluto, es exterior al mismo, al principio de autonomía (territorial y local), sino que la existencia de una tal publicidad nacional es probablemente una determinación positivamente exigida para garantizar el interés nacional que subyace en el principio de igualdad de acceso a las funciones públicas (artículo 23, 2, de la Constitución Española), y especialmente en el requisito establecido en el propio artículo 149, 1, 18, de la Constitución, al establecer el condicionamiento esencial de que las bases. que regulen el régimen jurídico de las Administraciones públicas y el régimen estatutario de sus funcionarios «garantizarán a los ad-

(31) En cuya virtud se han tratado de excepcionar permanentemente las Leyes generales en los territorios vascos, aunque, en la materia que nos ocupa, singularmente por las Diputaciones. Cfr. CASTElls: La Euskadi..., cit., esp. págs. 11 y sigs. Al tema se refiere también García-Trevijano: Tratado..., cit., III, II, págs. 1091 y sigs., desde otra perspectiva. 
LA FUNCION PUBLICA EN EL PROYECTO DE LEY REG. DE LAS BASES DEL REG. LOCAL 461

ministrados un tratamiento común ante ellas». Concepto éste de administrado que indudablemente incluye también aquí a los eventuales concursantes $u$ opositores al ingreso o a la provisión de puestos de trabajo en la Administración local (32).

No resulta bastante, en conclusión, a mi juicio, el sistema de reparto de competencias en materia establecido en la Constitución y en los Estatutos para impedir que el Estado pueda entender como básica la publicidad nacional de las convocatorias, como hace el Proyecto, en la medida en que tal cautela en ningún caso se puede entender violación de las facultades de desarrollo normativo de las Comunidades Autónomas ni mucho menos atentatoria de la autonomía municipal, respondiendo, por el contrario, a la necesidad, positivamente impuesta por la Constitución, de salvaguardar la igualdad y el tratamiento común de todos los ciudadanos. Se trata, pues, de una regla que respeta ambas autonomías, la de las Comunidades Autónomas y la local, y que resulta completamente acomodada a las facultades estatales de determinación de lo básico, a que más arriba me he referido.

(32) Otra solución violentaría seguramente aquellos derechos fundamentales, originando una posible cascada de recursos de amparo por parte de los interesados, la desestimación de cuyos recursos tendría ciertamente una difícil justificación. Cfr. L. ToLIVAR ALAS: «Estado-Corporaciones locales en la reciente jurisprudencia constitucional», REVISTA DE ESTUdIOS DE LA VIDA LOCAL, 221 (1984), págs. 143 y sigs. 
REVL-1984, núm. 224. BOCANEGRA SIERRA, RAUL. LA FUNCION PUBLICA EN EL PROYECTO D... REVL-1984, núm. 224. BOCANEGRA SIERRA, RAUL. LA FUNCION PUBLICA EN EL PROYECTO D... 